Société d'histoire de la révolution de 1848 et des

révolutions du XIXe siècle

$47 \mid 2013$

Quel est l'avenir du XIX $X^{\mathrm{e}}$ siècle ?

Bertrand GOUJON, Monarchies postrévolutionnaires, 1814-1848. Histoire de la France contemporaine, volume 2

L'univers historique, Paris, Le Seuil, 2012, 447 p. ISBN :

978-2-02-103 347-2. 25 euros.

François Jarrige

\title{
CpenEdition
}

Édition électronique

URL : http://journals.openedition.org/rh19/4591

DOI : 10.4000/rh19.4591

ISSN : $1777-5329$

Éditeur

La Société de 1848

Édition imprimée

Date de publication : 31 décembre 2013

Pagination : 204-205

ISSN : 1265-1354

Référence électronique

François Jarrige, «Bertrand GOUJON, Monarchies postrévolutionnaires, 1814-1848. Histoire de la France contemporaine, volume 2 », Revue d'histoire du XIXe siècle [En ligne], 47 | 2013, mis en ligne le 28 janvier 2014, consulté le 22 septembre 2020. URL : http://journals.openedition.org/rh19/4591 ; DOI : https:// doi.org/10.4000/rh19.4591

Ce document a été généré automatiquement le 22 septembre 2020

Tous droits réservés 


\section{Bertrand GOUJON, Monarchies postrévolutionnaires, 1814-1848. Histoire de la France contemporaine, volume 2}

L'univers historique, Paris, Le Seuil, 2012, 447 p. ISBN :

978-2-02-103 347-2. 25 euros.

François Jarrige

\section{RÉFÉRENCE}

Bertrand GOUJON, Monarchies postrévolutionnaires, 1814-1848. Histoire de la France contemporaine, volume 2, L'univers historique, Paris, Le Seuil, 2012, 447 p. ISBN :

978-2-02-103 347-2. 25 euros.

1 À force de répéter que la période décisive des monarchies censitaires est mal aimée et largement négligée dans la mémoire nationale, on en oublierait presque qu'elle a été l'une des plus fouillées par l'historiographie des trente dernières années. L'intérêt majeur de ce second volume de la nouvelle collection lancée aux éditions du Seuil sur l'histoire de la France contemporaine est de tenter une synthèse des nombreux travaux récents. Bertrand Goujon, maître de conférences à l'université de Reims ChampagneArdenne, est spécialiste de l'aristocratie et des élites européennes au XIX ${ }^{\mathrm{e}}$ siècle. L'ouvrage, qui assume son classicisme et sa focalisation sur le politique, est construit en six chapitres articulés aux grandes scansions politiques. Après l'étude des « retours des lys » (1814-1815), la description du «défi de l'apaisement et de la réconciliation nationale » (1815-1820) suivi de l'examen de la « réaction ultraroyaliste » (1820-1828), l'auteur étudie le passage "d'une monarchie à l'autre (1828-1832)», puis "l'enracinement du régime de juillet " jusqu'en 1840 et, finalement, «le glissement vers l'immobilisme du libéralisme conservateur» (1840-1848). On le voit, chacun des 
mots renvoie à des catégories bien établies dans l'historiographie de la période et dans l'imaginaire qui lui est associé.

2 L'ouvrage ne prétend à aucun bouleversement épistémologique, ni même à un véritable déplacement du regard sur la France du premier XIX ${ }^{e}$ siècle. Il entend d'abord « rendre compte de [la] remarquable floraison historiographique, trop souvent méconnue du grand public et exclue des feux médiatiques» (p.12). Ce livre est donc une tentative de synthèse à destination des étudiants et du grand public. Sans aller jusqu'à replacer la Restauration et la monarchie de Juillet au cœur des lumières médiatiques contemporaines - ce qui serait assurément impossible compte tenu de ce que sont ces dernières -, l'ouvrage parvient $d u$ moins très bien à expliquer les dynamiques politiques de la période 1814-1848 en les inscrivant en permanence dans les enjeux économiques et sociaux comme dans les transformations culturelles. À cet égard, il est réussi, d'autant que l'auteur manie une belle plume, claire et fluide, qui permet de le suivre avec intérêt dans son cheminement.

3 Le livre innove au moins par son titre: Monarchies postrévolutionnaires. Alors que la période était caractérisée dans les synthèses antérieures comme "la France des notables » (André Jardin et André-Jean Tudesq) ou par «l'avènement d'une France libérale» (Francis Démier), c'est la dimension « postrévolutionnaire » qui s'impose ici. Pourtant, cette formule aurait sans doute mérité d'être davantage justifiée, discutée et expliquée. Si l'auteur rappelle certes que la période est travaillée par de nombreuses "négociations compliquées avec un passé révolutionnaire et impérial qui ne passe pas » (p. 13), l'ombre révolutionnaire n'est guère interrogée pour elle-même. Les effets structurant de l'expérience révolutionnaire sur les imaginaires, les institutions, les dynamiques sociales du premier XIX siècle auraient pu être décrits de façon plus précise, d'autant qu'une vaste historiographie a traité de ce sujet. On peut aussi remarquer que la monarchie impériale, la plus postrévolutionnaire, n'est pas incluse dans ce volume. Comparant de façon pertinente, et classique, ces régimes aux "passages couverts » qui apparaissent précisément à cette époque à Paris, l'auteur insiste sur le fait que les monarchies censitaires ne peuvent pas se réduire à un simple entre-deux entre la révolution et la république: «ni simple transition, ni réaction anachronique », la période est au contraire traversée de dynamisme, de "vitalité ».

On regrettera, outre quelques coquilles peu nombreuses (comme cette grève des fileurs devenus «filateurs" rouennais de 1826, p. 205), que certaines formes de problématisation paraissent en retrait par rapport aux débats historiographiques. Ainsi est-il vraiment nécessaire d'évoquer les années 1840 comme « un moment charnière de la modernisation industrielle ", alors que c'est plutôt la singularité de la voie française qui interroge depuis trente ans les historiens de l'économie et du social, la valorisation du travail flexible dans un cadre artisanal, le dynamisme des structures protoindustrielles? Plutôt que de décrire l'histoire des économies du premier XIX ${ }^{e}$ siècle avec des catégories comme la "croissance », la « compétitivité », la "modernisation », il aurait justement été utile de discuter ces notions au regard de l'expérience française de l'époque. Davantage de réflexivité à cet égard aurait été d'autant plus utile que la question du langage a justement été souvent au cœur des travaux consacrés à cette période. On pourrait aussi regretter le peu de place accordé aux enjeux transnationaux, ou à l'expérience impériale qui s'engage. Peut-être s'agit-il d'un choix de l'éditeur, mais pourquoi tous les titres de la bibliographie sont-ils en français alors que l'un des déplacements majeurs de l'historiographie des trente dernières a été l'importance 
croissante des travaux anglo-américains? Il est également étonnant d'y trouver la synthèse que François Caron a consacrée aux «dynamiques de l'innovation technique » depuis le XVI" siècle, mais pas l'étude de Vincent Robert sur " le temps des banquets " ${ }^{1}$, pourtant si essentielle pour comprendre le fonctionnement politique de ces monarchies postrévolutionnaires.

5 Écrire une synthèse de cette qualité était une gageure, et les quelques remarques qui précèdent ne doivent pas dissimuler les nombreux atouts de l'ouvrage de Bertrand Goujon: l'ampleur des lectures, le sens de la synthèse et de la mesure, la qualité de l'écriture. Mais le meilleur accueil que l'on puisse réserver à une synthèse aussi ambitieuse, c'est sans doute de souligner ce qui apparaît aux yeux du lecteur comme des insuffisances. Écrire une histoire de France est un exercice périlleux, voire impossible, aujourd'hui plus qu'avant, et Bertrand Goujon a réussi le pari de restituer de façon vivante la complexité de ce moment de bouillonnement intellectuel, de ce laboratoire social et politique incessant, que fut la France du premier XIX ${ }^{e}$ siècle.

\section{NOTES}

1. François Caron, La dynamique de l'innovation. Changement technique et changement social (XVI ${ }^{e}-X^{e}$ siècle), Bibliothèque des histoires, Paris, Gallimard, 2010 ; Vincent Robert, Le temps des banquets. Politique et symbolique d'une génération (1818-1848), Paris, Publications de la Sorbonne, 2010 (compte rendu par Christophe Voilliot dans la Revue d'histoire du XIX ${ }^{e}$ siècle, $\mathrm{n}^{\circ} 42,2011 / 1$ (en ligne, URL : http://rh19.revues.org/4116). 